\title{
Are optometrists necessary in primary health care centres in Saudi Arabia?
}

\begin{tabular}{|c|c|}
\hline $\begin{array}{l}\text { Authors: } \\
\text { Yousef H. Alde } \\
\text { Mohammad I. } \\
\text { William A. Mo }\end{array}$ & $\begin{array}{l}\text { basi }^{1} \text { (0 } \\
\text { Ahmed }^{2} \\
\text { naco }^{3}\end{array}$ \\
\hline $\begin{array}{l}\text { Affiliations: } \\
{ }^{1} \text { Department } \\
\text { Qassim Unive } \\
\text { Saudi Arabia }\end{array}$ & $\begin{array}{l}\text { f Optometry, } \\
\text { sity, }\end{array}$ \\
\hline $\begin{array}{l}{ }^{2} \text { Department } \\
\text { Ophthalmolog } \\
\text { Specialist Hos } \\
\text { Saudi Arabia }\end{array}$ & $\begin{array}{l}\text { of } \\
\text { y, King Fahad } \\
\text { oital, }\end{array}$ \\
\hline $\begin{array}{l}{ }^{3} \text { College of He } \\
\text { Salus Universi } \\
\text { United States }\end{array}$ & $\begin{array}{l}\text { alth Sciences, } \\
\text { ty, }\end{array}$ \\
\hline $\begin{array}{l}\text { Correspondin } \\
\text { Yousef Aldeba } \\
\text { dbasy@qu.ed }\end{array}$ & $\begin{array}{l}\text { author: } \\
\text { si, } \\
\text { l.sa }\end{array}$ \\
\hline $\begin{array}{l}\text { Dates: } \\
\text { Received: } 071 \\
\text { Accepted: } 16 \\
\text { Published: } 26\end{array}$ & $\begin{array}{l}\text { May } 2017 \\
\text { Fet. } 2017 \\
\text { Feb. } 2018\end{array}$ \\
\hline $\begin{array}{l}\text { How to cite th } \\
\text { Aldebasi YH, A } \\
\text { Monaco WA. } \\
\text { optometrists } \\
\text { primary health } \\
\text { in Saudi Arabi } \\
\text { Eye Health. } 20 \\
\text { https://doi.org } \\
\text { aveh.v77i1.40 }\end{array}$ & $\begin{array}{l}\text { is article: } \\
\text { hmed MI, } \\
\text { re } \\
\text { lecessary in } \\
\text { care centres } \\
\text { ? Afr Vision } \\
18 ; 77(1) \text {, a402. } \\
\text { /10.4102/ } \\
\text { ? }\end{array}$ \\
\hline $\begin{array}{l}\text { Copyright: } \\
\text { (c) 2018. The A } \\
\text { Licensee: AOS } \\
\text { is licensed unc } \\
\text { Creative Comr } \\
\text { Attribution Lic }\end{array}$ & $\begin{array}{l}\text { uthor(s). } \\
\text { S. This work } \\
\text { ler the } \\
\text { hons } \\
\text { ense. }\end{array}$ \\
\hline Read online: & \\
\hline 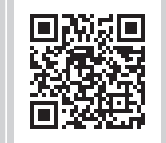 & $\begin{array}{l}\text { Scan this QR } \\
\text { code with your } \\
\text { smart phone or } \\
\text { mobile device } \\
\text { to read online. }\end{array}$ \\
\hline
\end{tabular}

Authors:

Affiliations:

Optometry

Qassim University,

${ }^{2}$ Department of

Ophthalmology, King Fahad

Specialist Hospital,

${ }^{3}$ College of Health Sciences, Salus University,

Corresponding author:

Yousef Aldebasi,

Dates:

Accepted: 16 Oct. 2017

How to cite this article: Aldebasi YH, Ahmed MI,

Monaco WA. Are ptometrists necessary in in Saudi Arabia? Afr Vision Eye Health. 2018;77(1), a402. https://doi.org/10.4102/

aveh.v77i1.402

Copyright:

Creative Commons

Attribution License.
Purpose: To determine the prevalence and visual characteristics of patients seen by optometrists and ophthalmologists in Saudi Arabian public hospitals. This model will demonstrate the efficacy, safety and effectiveness of optometrists as the primary point of contact for eye care in primary health care centres.

Methods: A retrospective, analytical, record-based study of patients in 10 hospitals in Saudi Arabia was conducted over a period of 6 months. The hospitals were located in 3 of 14 provinces in Saudi Arabia. The current policy is that ophthalmologists be the first point of contact for patients in all hospitals. Ophthalmologists, optometrists and nurses collected the data using a predesigned data collection sheet (Appendix 1) which was divided into four sections - basic data, ocular information, ocular diagnosis and intervention. The pattern of patient examination in the eye clinics in public hospitals was analysed. Additionally, patients' age, gender, nationality, symptoms, diagnosis and treatment were obtained from their medical records and considered for analysis. Diagnosis and treatment were classified by the scope of practice of optometrists and ophthalmologists: refraction, dispensing, rehabilitation of conditions of the visual system, detection, diagnosis and management of ocular diseases and referral to sub-specialty care were considered as optometric diagnoses. Prescription of medications and surgeries were classified as ophthalmologists' diagnoses.

Results: A total of 2601 patient records were reviewed from the pre-selected 10 public hospitals. There are approximately 415 public hospitals in Saudi Arabia. Refractive error was the most prevalent diagnosis; $54.5 \%$ of the patients were prescribed spectacles to relieve their symptoms of poor vision at distance and/or near. Around 35\% of patients received treatment in the form of medications $(20.6 \%)$, surgeries $(11.4 \%)$, contact lenses $(0.9 \%)$, orthoptics $(1.8 \%)$ and lowvision devices $(0.1 \%)$. About $0.6 \%$ patients were referred for major investigations such as ultrasonography, computed tomography and magnetic resonance imaging scans. No active intervention or treatment except observation was recommended for $7.7 \%$ of patients, and $2.4 \%$ of patients were referred to other sub-specialties. Based on the scope of practice and diagnostic criteria, the optometry discipline received the highest number of patients and can manage nearly $68 \%$ of patients registered for consultation; thus, they can take care of the predominant portion of eye-related problems in the outpatient services in the public hospital.

Conclusion: This study clearly demonstrates that because of the disproportionate number of patients seeking care with refractive problems, optometrists can manage about two-thirds of patients visiting eye clinics of public hospitals. Thus, suggesting the need for optometrists as initial point of contact in terms of eye care services in primary health care centres. This would minimise the work load and appointment delays in public hospitals. This model will also enhance the early detection of vision-threatening eye conditions and assure appropriate referral to prevent future complications.

\section{Introduction}

\section{Prevalence of visual impairment and blindness: Defining the visual problems across age groups}

Blindness and visual impairment are major global health care problems. A systematic review conducted by Pascolini and Mariotti ${ }^{1}$ showed that 285 million people (of all ages) are visually impaired because of uncorrected refractive errors (43\%), followed by cataract (33\%). Among those 285 million, 39 million are blind and 246 million are partially sighted. ${ }^{1}$ Approximately 228 million (80\%) people worldwide are avoidably visually impaired. ${ }^{1}$ In the Eastern Mediterranean Region, the World Health Organization (WHO) estimates that about 5 million (13\%) are blind. ${ }^{1}$ Tabbara ${ }^{2}$ estimated that $1.5 \%$ of the total population and over $20 \%$ of the population older than 60 years of 
age were blind in Saudi Arabia. ${ }^{2}$ A study conducted in AlJouf province showed that prevalence of blindness according to $\mathrm{WHO}$ criteria was $0.8 \%$ and visual impairment was $13.9 \%$, with the main causes being refractive errors $(36 \%)$, cataract (29.1\%) and diabetic retinopathy (DR) (20.9\%), while the least common cause was glaucoma $(5.8 \%))^{3}$

\section{Visual impairment in school-aged children}

Aldebasi $^{4}$ reported that the prevalence of refractive error was $18.6 \%$ among primary school children in Qassim, Saudi Arabia. Of the $18.6 \%$, approximately $2.3 \%$ were already wearing spectacles, which indicates that less than $5 \%$ of those needing refractive correction were wearing spectacles. ${ }^{4}$ Uncorrected refractive error was the primary contributor in $93.9 \%$ of those students with visual acuity of $20 / 40$ or worse and $94.6 \%$ of those students diagnosed with amblyopia. The prevalence of uncorrected refractive error in Qassim primary school children $(16.3 \%)$ was higher than that in geographic areas with broad screening programmes such as Kelantan in Malaysia $(7.0 \%),{ }^{5}$ Guangzhou $(9.8 \%)^{6}$ and Shunyi $(9.7 \%)^{7}$ districts in China, Cairo in Egypt $(12.7 \%)^{8}$ and Al-Hassa in Saudi Arabia $(12.4 \%)^{9}$ in children of similar age ranges. The prevalence of amblyopia varies regionally in Saudi Arabia ranging from $1.3 \%$ to $3.3 \% .^{10,11}$ The prevalence of amblyopia in Qassim primary school children (3.9\%) was higher than that of China $(1.19 \%),{ }^{12}$ Australia $(1.9 \%),{ }^{13}$ USA $(2.6 \%),{ }^{14}$ Iran $(2.28 \%),{ }^{15}$ Pakistan $(3.0 \%)^{16}$ and UK (3.6\%) ${ }^{17}$

\section{Visual impairment in adults}

It has been estimated that $65 \%$ of people aged 50 years and older are visually impaired and $82 \%$ are blind. ${ }^{1}$ Reasons for higher prevalence of visual impairment in elderly people include the need for spectacles, ocular disease and lack of referral. ${ }^{18}$ In 2010, approximately $65 \%$ of 32.4 million blind people and $76 \%$ of 191 million people with moderate to severe visual impairment worldwide had avoidable vision loss because of cataract, uncorrected refractive error, trachoma, glaucoma and DR. ${ }^{19}$ Leading causes of blindness and moderate to severe visual impairment among adults aged $\geq 50$ years were cataract $(33 \%$ and $18 \%$, respectively), uncorrected refractive error (21\% and 53\%) and macular degeneration (7\% and $3 \%) .{ }^{19} \mathrm{DR}$ is the fifth most common cause of blindness and moderate to severe visual impairment in adults aged 20-74 years..$^{20}$ In Saudi Arabia, refractive error $(36.0 \%)$ was the leading cause of visual impairment followed by cataract $(29.1 \%)$, DR $(20.9 \%)$ and glaucoma $(5.8 \%)$ in the adult population who attended the primary health care centres. ${ }^{3}$ The Saudi Ministry of Health $(\mathrm{MOH})$, in collaboration with the National Prevention of Blindness Committee (NPBC), conducted rapid assessments of avoidable blindness and DR (RAAB+DR) in which persons aged 50 years and older were examined. ${ }^{21}$ The results showed that the prevalence of blindness was $2.6 \%$ and diabetes was $29.7 \%$. In diabetes, the prevalence of DR was $36.8 \%$ and sight threatening DR (STDR) was $17.5 \%{ }^{22}$ The standardised risk of having DR for a 50 -year-old man was $1.1 \%$ in Saudi Arabia. ${ }^{23}$ Diabetic retinopathy is a growing public health problem in Saudi Arabia and a planned approach is required to prevent severe visual impairment in patients with diabetes mellitus (DM). ${ }^{24}$

\section{Global action plan - Saudi Arabia work towards universal eye health}

In Saudi Arabia, $\mathrm{MOH}$ is committed to providing health care at all levels, promoting health and preventing disease..$^{25}$ In alignment with prevention is early detection and treatment. In addition, the $\mathrm{MOH}$ is responsible for developing the laws and policies regulating governmental and private health sectors. ${ }^{25}$ Blindness prevention has been incorporated into Saudi Arabia's new primary health care policy. ${ }^{25}$ There is a dedicated budget and training schedules in this health care policy and efforts to provide and maintain continuous eye care. ${ }^{25}$ A 5-10 year programme is being developed within existing health structures for screening of pre-school children's vision, DR, retinopathy of prematurity (ROP), glaucoma and cataract. ${ }^{21}$ Ministry of Health has activated its prevention of blindness (PB) unit to areas responsible for public health and non-communicable diseases based on data indicating increases in blindness rate, primarily from $\mathrm{DR}$, which was demonstrated by the RAAB+DR study. ${ }^{22}$ In 2013, \$2.66 million USD was allocated specifically for DR screening, the development of protocols for glaucoma, ROP and pre-school screening and additional research to prevent blindness. ${ }^{21}$ Optometrists play a vital role in detecting refractive error, glaucoma and DR screening in both more or less developed countries. ${ }^{24,26,27,28,29,30}$

\section{Primary eye care and role of optometry}

Primary eye care is a front-line activity and an integral part of comprehensive eye care that is targeted not only towards preventing blindness and visual impairment but also providing services to reduce ocular morbidity. ${ }^{31}$ Primary eye care services include the following: ${ }^{31}$

- eye health education

- symptom identification

- visual acuity measurement

- ocular refraction

- screening for eye conditions affecting vision that may be asymptomatic

- recognising ocular manifestations of systemic diseases and systemic effects of ocular medications

- diagnosis

- timely referral.

Adequately qualified practitioners, expert management and decision-making skills are crucial in promoting the quality and efficiency primary eye care. ${ }^{31}$ Primary care optometry includes the components of visual care, ocular health and care associated with related systemic diseases. Optometrists have many roles in the management of eye disorders apart from refraction and visual rehabilitation; they are capable of monitoring disease progression and providing timely follow-up examinations for management of ocular disorders 
associated with systemic diseases such as diabetes and hypertension. Optometrists also make appropriate referrals for sub-specialty care when indicated, and, above all, they are vital for patient education. Optometric participation, as a member of the interdisciplinary team, will enhance early detection and appropriate, timely referral, thereby potentially preventing further disease complications. Hence, an optometrist is the logical primary gatekeeper of world eye care, contributing a known but flexible set of defined professional skills and ethics in a most effective and cost-efficient way. ${ }^{32}$

Uncorrected refractive error is the most common cause of visual impairment and the leading cause of treatable blindness in adults and children in Saudi Arabia.,4,10,11,33 Fortunately, refractive error can usually be simply diagnosed, measured and corrected at the primary eye care level by an optometrist and the provision of spectacles is an extremely effective intervention, providing immediate correction of the problem. Globally, eye care is undergoing rapid changes because of emerging technology and innovation. ${ }^{34}$ Therefore, both professional personnel (ophthalmologists, optometrists, nurses and technicians) and technology should be used appropriately to address visual impairment and blindness in Saudi Arabia. The proposed eye care delivery model is strategically designed to reduce patient waiting times and the workload for ophthalmologists and resulting in improved patient outcomes.

The WHO recommends that there is a need of at least one optometrist per 100000 people by 2010 and 1:50 000 by the year 2020.35,36 The most developed countries (USA, UK, Australia and Canada) have far exceeded this minimum target of optometrists to population and have a ratio of approximately 1:10 000 (Table 1). ${ }^{36,37,38}$ In developed countries, optometrists are often the first point of professional contact for people experiencing ocular problems and most of the optometrists are working in independent practice in private practice settings, public clinics or at health care institutions such as hospitals, community health centres, corporate optometry settings, research, teaching and administration. ${ }^{26,27,28,29,30,38}$ In the USA, optometrists perform $85 \%$ of all comprehensive eye exams annually and prescribe $90 \%$ of vision correction devices. ${ }^{27}$ Optometry is an integral part of the primary health sector and optometrists are the largest eye care health workforce in the $\mathrm{UK}^{39}$ and Australia. ${ }^{28}$ In developing countries, WHO estimated the optometrist to population ratio as 1:600 $000 .^{38}$ In Saudi Arabia, Al Motowa et al. ${ }^{40}$ indicated that there is one optometrist per 95000 of the population (Table 1). ${ }^{40}$ This ratio falls far short of the best-practice international

TABLE 1: Comparison ratios of optometrists to patients in different countries and Saudi Arabia (American Academy of Optometry), 2008. ${ }^{35}$

\begin{tabular}{lll}
\hline SI. number & Country & Optometrist: Number of patients \\
\hline 1 & UK & $1: 10000$ \\
2 & USA & $1:<8333$ \\
3 & Australia & $1: 7500$ \\
4 & KSA $^{40}$ & $1: 95500$ \\
\hline
\end{tabular}

KSA, Kingdom of Saudi Arabia. benchmark of countries such as USA, UK and Australia. However, in Saudi Arabia, the services provided in public eye clinics do not place a priority on the optometrist as the primary eye care provider because the primary point of contact for the patients are ophthalmologists.

Comparison of number of optometrists versus number of patients from different countries and Saudi Arabia is shown in Table $1 .^{35,40}$

\section{Current scenario in eye care access in Saudi Arabia}

Eye care services are delivered at public and private hospitals by Saudi professionals as well as professionals from other countries. ${ }^{40}$ The current patient flow pattern in public eye clinics in Saudi Arabia is depicted in Figure 1. In public hospitals, eye examinations are carried out by ophthalmologists who are posted in screening clinics or ophthalmology (outpatient) clinics. The ophthalmologists serve as the entry point for all patients who want to have an eye examination. The general physicians from primary care centres refer patients to the eye clinic or hospitals for treatment. If the ophthalmologists, who screen the patients, determine that the diagnosis is an optometric issue, a second appointment is scheduled in the same hospital. This referral practice has been in use since 1970 in the Kingdom of Saudi Arabia. ${ }^{41}$ This eye care strategy is plagued by long waiting times and delays in care. The approximate waiting time for a patient to access primary eye care in public hospitals probably ranges from 2 to 4 months.

Therefore, the aims of this study are firstly to determine the frequency and prevalence of visual characteristics of patients seen by optometrists in Saudi Arabian public hospitals and secondly to substantiate the need for expanding the model and incorporating optometrists in all primary health care centres.

\section{Methods}

A retrospective chart review of medical record charts was performed in 10 hospitals. A sample of 260 complete patient records was obtained by systematic random sampling method in which the patient records from each hospital was selected according to a random starting point and a fixed, periodic interval from September 2011 to February 2012. The data from each of the selected hospitals were reviewed for the patient flow data as well as clinically significant ocular findings documentation during the patient visits. This study was limited to the assessment of outpatient visits and the analysis of cases where both optometrists and ophthalmologists provided service. A standard exam form (Appendix 1) was developed and an ophthalmologist, optometrist or a nurse collected and recorded the data from the patient's registration, consultation in screening, ophthalmological assessment or optometry consultation. The data were divided into four sections: patient information (age, gender, nationality and place of assessment), ocular information (included history, information about spectacles, objective and subjective refraction, pupillary 


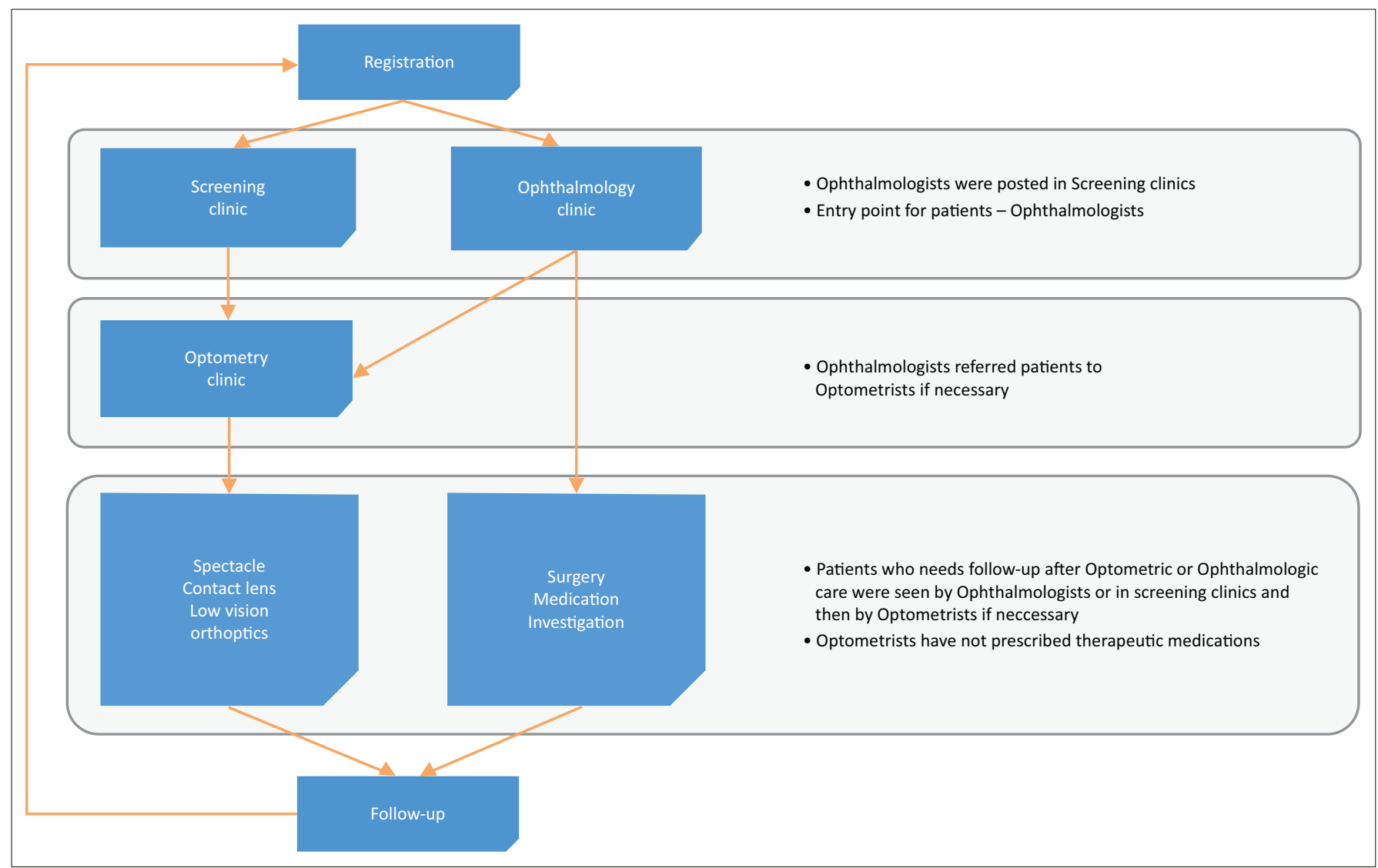

FIGURE 1: The current patient flow pattern in public eye clinics in Saudi Arabia.

assessment, cover test, anterior and posterior segment examination findings and intraocular pressure readings), ocular diagnosis (recorded in the patient's medical record) and intervention (treatment plan). A provisional diagnosis was determined based solely on the information available from the patient's records. Treatment was categorised according to the accepted evidence-based criteria for standard of care of the optometrist or ophthalmologist. Refraction, dispensing, rehabilitation of conditions of the visual system, detection, diagnosis and management of ocular diseases and referral to sub-specialty care were considered as optometric diagnoses. Prescription of medications and surgeries were classified as ophthalmologic diagnoses.

\section{Definitions}

Refractive errors: Patients were considered to have refractive errors if spectacle prescriptions were given to improve their visual acuities for distance and/or near.

Low vision: Patients with moderate $(20 / 70-20 / 200)$ or severe visual impairment (20/200-20/400) in the better eye were diagnosed to have low vision, based on the legal definition. ${ }^{42,43}$

Surgery: Any invasive procedure performed in either eye that was documented in the patient's chart, including refractive surgery.

The collected data were tabulated using Microsoft Excel software and analysed using SPSS version 15 (SPSS for
Windows, SPSS 15.0.1, SPSS Inc., Chicago, IL). The data are presented in a descriptive statistical format. The percentage of different age groups, ocular symptoms, provisional diagnosis and treatment options were calculated for the total patient population studied.

\section{Ethical considerations}

This study was approved by the local Ethics Committee and the need for informed consent was waived.

\section{Results}

\section{Patient profiles}

The total patient sample was 2601 (approximately 260 complete patient records from each participating hospital). Twenty-five hundred and two (96\%) patients were Saudi and $99(4 \%)$ were non-Saudi. About $52 \%(N=1356)$ of the patients were men. The age group distribution was infancy to age 60 (see Table 2). The variables considered in the analysis were (1) chief complaint, (2) diagnoses, (3) treatment and (4) referrals.

The symptoms reported by the patients were decreased vision, ocular irritation, headache, flashes and floaters, and routine eye exam visits. Forty-four per cent of the patients have a decrease in vision for distance and/or near, $22 \%$ ocular irritation, $17 \%$ headache, $2 \%$ flashes and floaters, and $15 \%$ of the patients were for routine exam visits. The percentage of patients who reported symptoms during their visits is shown in Figure 2. 
TABLE 2: Distribution of age for patients who visited the Saudi Arabian public eye care clinics over the 6 month period of the study.

\begin{tabular}{lccc}
\hline Age group (in years) & $N_{\dagger}^{*}$ & $\%$ & {$[95 \% \mathrm{Cl}+$} \\
\hline $0-10$ & 387 & 14.9 & $13.5-16.3$ \\
$20-30$ & 378 & 14.5 & $13.1-15.8$ \\
$21-30$ & 345 & 13.3 & $11.9-14.6$ \\
$31-40$ & 210 & 8.1 & $7-9.1$ \\
$41-50$ & 371 & 14.3 & $12.9-15.6$ \\
$51-60$ & 379 & 14.6 & $13.9-15.9$ \\
$61-70$ & 342 & 13.1 & $11.8-14.4$ \\
$71-80$ & 141 & 5.4 & $4.5-6.3$ \\
$81-90$ & 41 & 1.6 & $1.1-2.1$ \\
$91-100$ & 7 & 0.3 & $0.1-0.5$ \\
\hline
\end{tabular}

$\dagger, N$ indicates the number of cases; $\downarrow$, Case percentage, and in parentheses $95 \%$ confidence interval.

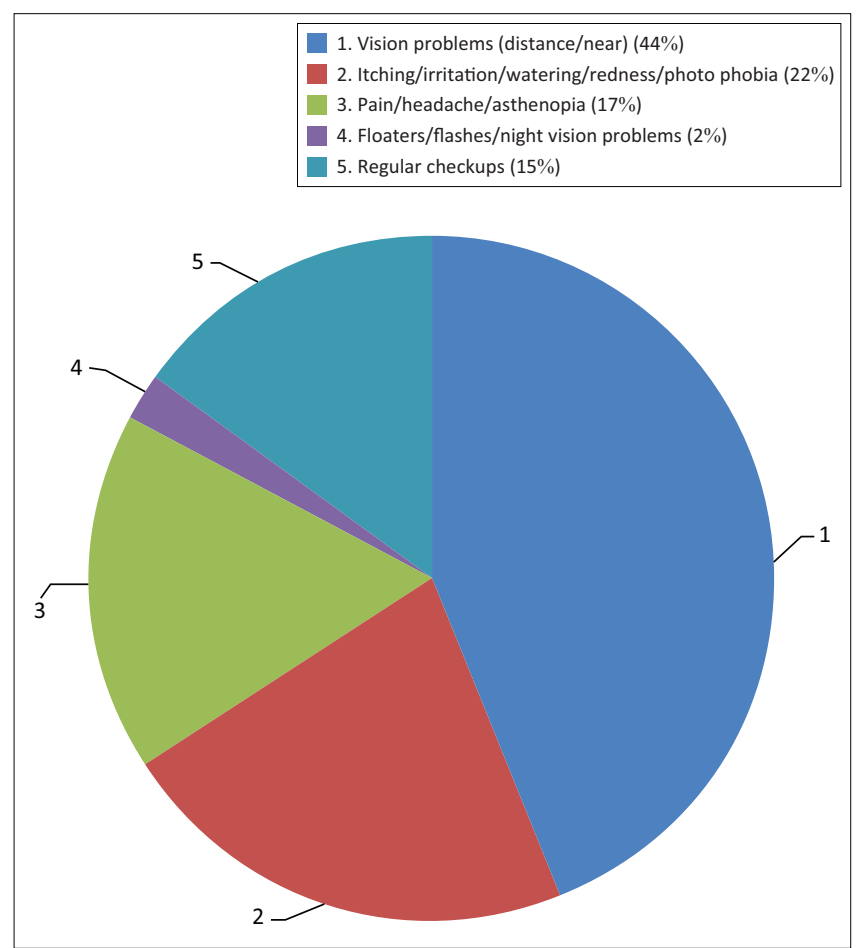

FIGURE 2: Percentage of patients who reported symptoms during their visit.

From Figure 3, it is clear that of the 2601 patients, refractive error was the most prevalent diagnosis $(59.4 \%)$, followed by ocular pathologies $(35.3 \%)$ and low vision $(1 \%)$, while the remaining patients $(4.3 \%)$ were found, by ophthalmological exam, to have normal vision.

The options for treatment included spectacles, contact lenses, low-vision devices, orthoptics, medications, surgery, special diagnostic testing and major investigations such as ultrasonography, computed tomography (CT) and magnetic resonance imaging (MRI) scan; referrals and treatment options for all patients who visited eye clinics are shown in Table 3. Around $54.5 \%$ of the patients were prescribed spectacles to relieve their symptoms of poor vision at distance and near. Around 35\% patients received treatment in the form of medications (20.6\%), surgeries (11.4\%), contact lenses $(0.9 \%)$, orthoptics $(1.8 \%)$ and low-vision devices $(0.1 \%)$. Only $0.6 \%$ patients were referred for major investigations such as ultrasonography, CT and MRI scans. No active intervention or treatment except observation was recommended for

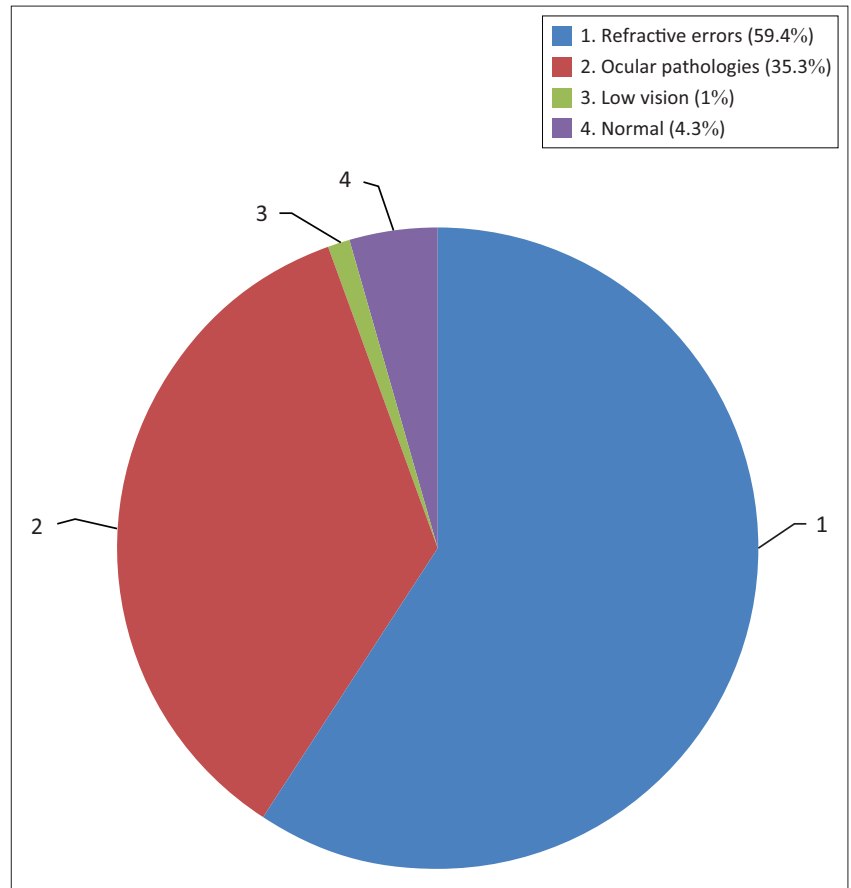

FIGURE 3: Percentage of ocular disorders diagnosed during the consultation.

TABLE 3: Treatment options provided for the patients who visited public eye care clinics.

\begin{tabular}{lccc}
\hline Treatment & $\boldsymbol{N} \dagger$ & $\mathbf{\%}$ & {$[95 \% \mathrm{Cl}]$} \\
\hline Spectacles & 1589 & 54.5 & $52.7-56.3$ \\
Contact lens & 26 & 0.9 & $0.6-1.2$ \\
Low-vision aids & 2 & 0.1 & $-0.01-0.2$ \\
Orthoptics & 54 & 1.9 & $1.4-2.4$ \\
Medications & 601 & 20.6 & $19.1-22.1$ \\
Nil intervention & 225 & 7.7 & $6.7-8.7$ \\
Surgery & 333 & 11.4 & $10.3-12.6$ \\
Major investigations & 16 & 0.5 & $0.2-0.8$ \\
Referrals & 69 & 2.4 & $1.8-3.0$ \\
\hline
\end{tabular}

$\dagger, N$ indicates the number of cases; $\$$, Case percentage, and in parentheses $95 \%$ confidence interval.

$7.7 \%$ patients and $2.4 \%$ of patients were referred to other subspecialties. The percentages of interventions received by the patients are shown in Table 3.

Treatments such as spectacle correction, contact lenses, lowvision aids, binocular vision assessment and appropriate referral to ophthalmologists were classified as optometric treatment. Treatments such as surgery, medical exams and prescription of medications were classified under ophthalmology. About $68 \%$ of the patients seen were managed by providing spectacle correction, contact lenses, vision therapy, low-vision assessment, nil active intervention and/or observation, or referral to other sub-specialties. Based on the scope of practice and diagnostic criteria (as mentioned in the 'Methods' section), optometry received the highest number of patients and can manage nearly $68 \%$ of patients registered for consultation; hence, they can take care of the predominant portion in the outpatient services of public hospitals. While in both screening and ophthalmology clinics, ophthalmologists and nurses provide the medical and surgical eye care available, and general nurses assist ophthalmologists in technical tasks such as visual acuity assessment, auto-refraction, intraocular 
pressure measurement and assist with hospital or in-office surgery. The remaining 32\% of patients were managed with medication, surgery and referral for major investigations.

\section{Discussion}

In both screening and ophthalmology clinics, ophthalmologists are the first point of eye care for the patients who visit outpatient departments in public hospitals (as shown in Figure 1). The prescription for spectacles requires a referral to the optometrist by ophthalmologist. This protocol makes the system complicated and prolongs patient appointments and waiting times for patients who just need correction for refractive error. Many of the patients could still be seen by optometrists before referral to ophthalmologists for further assessment and treatment. Perhaps, we suggest a new model for the future where ophthalmologists would not be needed at the screening clinics (Figure 4) in replacement of current patient flow pattern in public eye clinics (as shown in Figure 1). When optometrists provide primary eye care in the screening clinics and/or in community, there is often no need for referral to ophthalmologists for eye care. Fewer referrals will minimise the workload of ophthalmologists in public hospitals and decrease patient waiting times and this would be particularly important in terms of more effective management of eye diseases such as cataract and DR.

\section{Optometric treatment}

This study clearly demonstrates that refractive errors were the most prevalent ocular findings. This finding is consistent

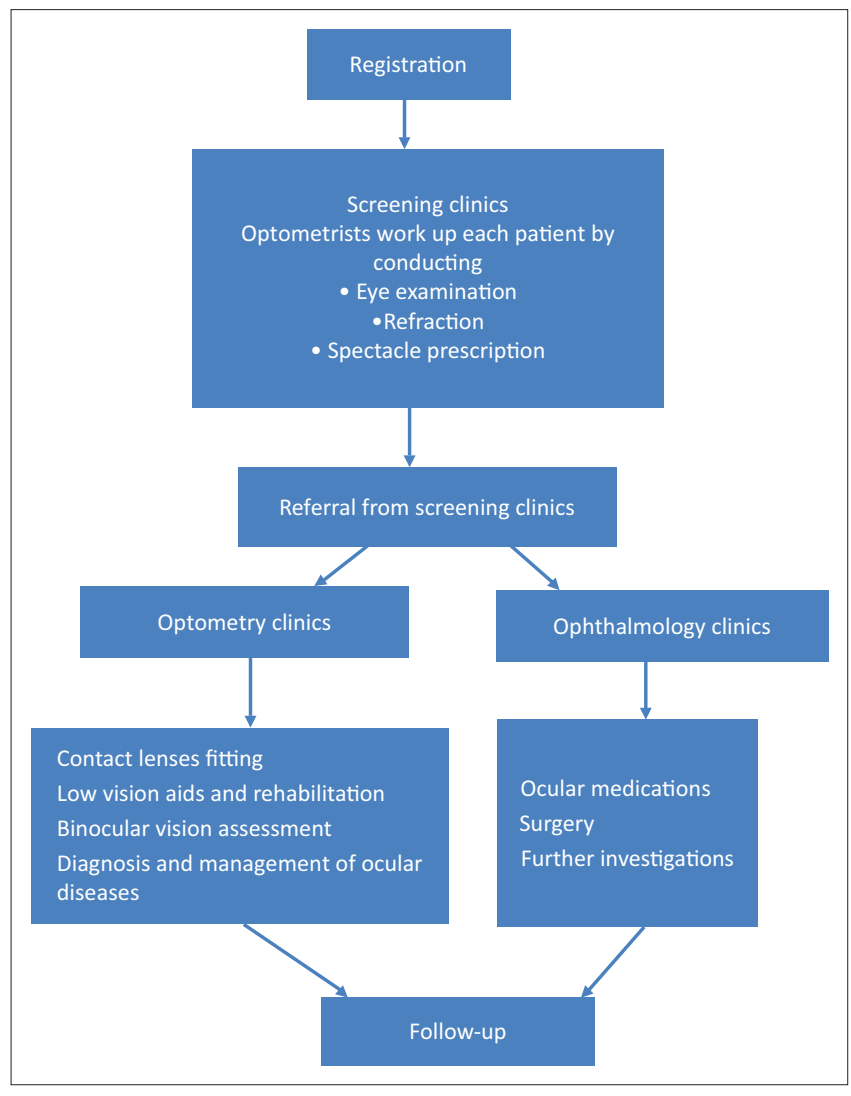

FIGURE 4: New work flow pattern suggested for Saudi Arabian public eye clinics. with other studies conducted in Singapore, Brazil and India, showing that refractive error is the primary cause of visual impairment in younger and older persons. ${ }^{44,45,46}$ Moreover, our results clearly demonstrate that the major portion of treatment for eye disorders is the prescription of spectacles (54.5\%). A study conducted in Norway showed that $60 \%$ of advised treatment was spectacle prescription; vision training was $12 \%$, further follow-ups was $30 \%$ and referral to ophthalmologist was $4 \%$ for the children under 15 years. ${ }^{47}$ Similarly, Aldebasy ${ }^{4}$ reported that the refractive error contributed to $93.9 \%$ of uncorrected visual acuity of $20 / 40$ or worse and $94.6 \%$ of amblyopia among primary school children. The high prevalence of refractive error in many studies further substantiates the fact that most patients in Saudi and other public hospitals seek eye care for the correction of refractive error. Poor visual acuity and poor contrast sensitivity or reduced stereopsis increase the frequency of anomalies of balance and are important predictors of falls in older adults. ${ }^{48,49}$ Older adults with visual impairment should be examined regularly to prevent further decline in their sight to ensure the best quality of life and to decrease the risk of falls. ${ }^{49,50}$ All older people undergoing a falls assessment should be screened for visual impairment. ${ }^{18}$ Hence, older adults should have a yearly comprehensive eye examination in order to preserve vision for their lifetimes. Optometrists are specially trained and have a unique role to play in the delivery of eye care services in our community by treating refractive error and providing spectacles. Hence, there is a need for optometric participation in primary eye care centres and establishment of optometry clinics in primary eye care facilities (as shown in Figure 4). Our study findings reinforce that the optometric services provided at the entry points in the primary health care system in Saudi Arabia will improve the quality of eye care rendered and reduce the cost of providing eye care services to the community.

\section{Ophthalmology treatment}

Thirty-five per cent of the examined patients exhibited some form of pathology. The most common ocular pathologies were corneal opacities, cataract and retinal disorders. Similarly, Schellini et al. ${ }^{45}$ showed that although the main cause of low vision was refractive error $(72.3 \%)$, cataract was the most prevalent cause of blindness (50\%). Al-Shaaln et al. $^{3}$ further substantiated that the main cause of visual impairment was refractive error $(36 \%)$, cataract $(29 \%)$ and DR (20\%).

\section{Role of optometry in integrated eye care}

The proposed strategy recommends that optometrists serve as primary eye care providers and the initial point of contact for Saudi patient's seeking eye care. This proposal, if implemented, will decrease the workload of ophthalmologists in eye clinics and allow them to concentrate their care and services on areas where they are especially trained and skilled, that is, surgery and specialty medical eye care. 
Optometry is an independent and regulated profession in countries such as Australia, Hong Kong, Malaysia, Mauritius, New Zealand, Philippines, Nigeria, South Africa, Netherlands, Scandinavia, UK, Canada, Mexico and the US. ${ }^{51}$ Optometrists deliver nearly $70 \%$ of comprehensive eye care and $90 \%$ of primary eye care services in countries with mature eye care systems. ${ }^{26,27,28,29,30,39}$ Particularly, optometry has contributed in reducing the burden of blindness and visual impairment because of uncorrected refractive error. ${ }^{38}$ In Australia, optometrists are the initial point of contact for primary eye care services; however, optometrists are not utilised in great numbers in hospitals. ${ }^{28}$ The majority of optometrists practice in the private sector, so the supply and demand for optometrists is largely determined by market forces. ${ }^{28,29}$ A survey conducted by the American Optometric Association confirmed that most optometrists $(71.3 \%)$ are private practitioners, providing eye care in private solo practices, group practices and partnerships. ${ }^{27}$ In many developed countries, optometrists deliver eye care services to the community from private practice, hospital eye departments and community clinics, but private practice still dominates the optometric profession. ${ }^{27,28,29,30}$ Optometrists, as primary eye care providers, are widely distributed in communities; and can also serve as the entry point in the eye care system for many patients around the world. ${ }^{27,28,29,30,35,38,39}$

However, in Saudi Arabia, the services provided in public eye clinics do not place the same priority on optometry as the primary eye care provider. The initial point of contact for eye care is ophthalmologists. Private practice optometry in Saudi Arabia is not well established and most optometrists are working in either public and / or private hospitals. Optometrists are also not fully utilised in the primary health centres and there is minimal participation in solo private or group practice..$^{24}$

The eye care delivery model that we propose allows each practitioner, optometrist or ophthalmologist, to function at their highest professional level. In the USA, there are two basic models that are followed by many ophthalmologists and optometrists. ${ }^{34}$ In one model, the optometrist and ophthalmologist are co-located in the same practice. ${ }^{34}$ The optometrist works up each patient by conducting the major portion of the eye exam, fitting contact lenses, writing spectacle prescriptions and medical diagnosis and management of eye disease. ${ }^{34}$ The ophthalmologist then sees the patient if tertiary or more specialised care is required. In another, commonly encountered model, the optometrists have their own practices and their own patients, and ophthalmologists never see the patients until there is a medical or surgical need. ${ }^{27}$ With this example, the surgeon is freed to spend most of their time in the operating room, instead of conducting routine eye examinations. This model allows more patients to benefit from the surgeon's unique expertise. The ophthalmologist and population ratio in Saudi Arabia is considered to be too low. ${ }^{40}$ Moreover, the available ophthalmologists often manage ocular conditions that could be handled by optometrists. The current eye care practice in private and public hospitals may generate an additional pressure on the available ophthalmologic workforce in dealing with major surgical cases and affects eye care services. To fully address the patient needs, a qualified and skilled optometrist should be posted in the screening clinics to perform comprehensive eye exams, diagnose the ocular disorders, distinguish those patients who require more specialised medical or surgical care and refer patients for tertiary care and/or appropriate sub-specialties that consequently decrease the time required by an ophthalmologist to see each patient. In this practice model, the vast majority of eye care rendered by the ophthalmologists will be a higher level of consultation and surgery, not the routine exams, Intraocular pressure (IOP) checks or postoperative exams. Optometrists can be utilised in eye clinics or in a community based network settings as primary eye care providers because of increased patient demands for eye care and cutting-edge advancements in eye care technology. Hence, we suggest the integrated eye care model, in which optometrists and ophthalmologists work under the same roof, but the point of entry for eye care should be an optometrist in the health care system to rectify the possible shortage of ophthalmologists and optometrists in Saudi Arabia.

Saudi optometrists are primary eye care providers who should occupy a distinctive position in health care centres to render clinical services in the areas of spectacles, contact lenses, low vision, binocular vision and occupational vision care. Placing a well-educated optometrist in primary eye care clinics as a comprehensive primary eye care provider will result in the best possible eye care for patients in these settings. ${ }^{52}$ Hence, we suggest that optometrists should be recognised as a principal provider of eye and vision care services within the health care management model as they are accessible, comprehensive and culturally effective providers of eye and vision care.

\section{Conclusion}

This study clearly demonstrated that almost two-thirds of the eye care in eye clinics of 10 high-volume (or representative) public hospitals could be done by optometrists. We propose, based on the findings of this study, that the point of entry for initial eye care in all public hospitals be an optometrist. It is crucial that optometrists should be recognised as principal eye care providers of comprehensive patient-centred eye care. When optometrists work together with physicians in primary health care centres or with ophthalmologists in public hospitals, patients can access both primary and surgical eye care services in a timely, efficient manner on their initial visit, eventually resulting in high patient satisfaction. The inclusion of optometry in the health care system as an entry point of patient care can improve the costeffectiveness of the health services. ${ }^{39,52}$ In conclusion, the eye care needs of Saudis can be addressed by engaging optometrists in a care delivery model that is collaborative, professionally fulfilling and highly competent in providing a large volume of quality eye care to the community. This approach would potentially result in reduction in waiting times from 2 to 4 months to a few days for an optometric or ophthalmologic appointment and also reduce the excessive workload of ophthalmologists and focus it on the procedures that only they can perform. 


\section{Recommendations}

We propose that the first point of contact for patients visiting the outpatient eye departments in hospitals in Saudi Arabia be optometrists. All primary care centres should have optometrists. Optometrists will enhance the early detection, referral and treatment of all ocular disorders and work to prevent future ocular complications. This approach would result in time savings and reduce excessive workloads of ophthalmologists. Ensuring good patient management would reduce waiting times and provide better access and appropriate eye care for every patient. We recommend that for Saudi Arabia between 10 and 25 optometrists per region should be placed in the relevant applicable primary health care centres to demonstrate the effectiveness of this eye care delivery system.

\section{Acknowledgements}

The authors would like to thank the hospital managements and ophthalmologists, optometrists and nurses who helped in collecting the data. The authors are grateful to Professor Kovin Naidoo and Professor Di Stefano for their extremely valuable expert opinions in reviewing the manuscript. The authors thank Naganathan Muthuramalingam, Vishakh G. Nair and Priya R. Reddy, faculty members of their department, for their valuable input in making this study possible. Deanship of Scientific Research of Qassim University funded this study.

\section{Competing interests}

The authors declare that they have no financial or personal relationships that may have inappropriately influenced them in writing this article.

\section{Authors' contributions}

Y.H.A. was responsible for substantial contributions to design, acquisition of data, analysis and interpretation of data, drafting of the article, revising the article critically for important intellectual content and final approval of the version to be published. M.I.A. was responsible for revising the article critically for important intellectual content and final approval of the version to be published. W.A.M. was responsible for substantial contributions to conception and designs, drafting of the article, revising the article critically for important intellectual content and final approval of the version to be published.

\section{References}

1. Pascolini D, Mariotti SP. Global estimates of visual impairment: 2010. Br J Ophthalmol. 2012;96(5):614-618.

2. Tabbara KF. Blindness in the eastern Mediterranean countries. Br J Ophthalmol 2001;85(7):771-775

3. Al-Shaaln FF, Bakrman MA, Ibrahim AM, Aljoudi AS. Prevalence and causes of visual impairment among Saudi adults attending primary health care centers in northern Saudi Arabia. Ann Saudi Med. 2011;31(5):473-480. https://doi org/10.4103/0256-4947.84624

4. Aldebasi YH. Prevalence of correctable visual impairment in primary school children in Qassim Province, Saudi Arabia. J Optom. 2014;7(3):168-176.
5. Hashim SE, Tan HK, Wan-Hazabbah WH, Ibrahim M. Prevalence of refractive error in Malay primary school children in sub-urban area of Kota Bharu, Kelantan, Malaysia. Ann Acad Med Singapore. 2008;37:940-946.

6. He M, Zeng J, Liu Y, Xu J, Pokharel GP, Ellwein LB. Refractive error and visual impairment in urban children in southern China. Invest Ophthalmol Vis Sci. 2004;45:793-799.

7. Zhao J, Pan X, Sui R, Munoz SR, Sperduto RD, Ellwein LB. Refractive error study in children: Results from Shunyi District, China. Am J Ophthalmol. 2000;129:427-435.

8. El-Bayoumy BM, Saad A, Choudhury AH. Prevalence of refractive error and low vision among schoolchildren in Cairo. East Mediterr Health J. 2007;13 575-579.

9. Al Wadaani FA, Amin TT, Ali A, Khan AR. Prevalence and pattern of refractive errors among primary school children in Al Hassa, Saudi Arabia. Glob J Health Sci. 2012;5:125-134.

10. Abolfotouh M, Faheem Y, Badawi I, Khairallah S. Ocular disorders among school boys in a high altitude area of Saudi Arabia. Saudi J Ophthalmol. 1994;8(3):20-24.

11. Aldebasi YH. Prevalence of amblyopia in primary school children in Qassim Province, Kingdom of Saudi Arabia. Middle East Afr J Ophthalmol. 2015;22(1):8691. https://doi.org/10.4103/0974-9233.148355

12. Chia A, Dirani M, Chan Y, et al. Prevalence of amblyopia and strabismus in young Singaporean Chinese children. Invest Ophthalmol Vis Sci. 2010;51:3411-4317. https://doi.org/10.1167/iovs.09-4461

13. Pai AS, Rose KA, Leone JF, et al. Amblyopia prevalence and risk factors in Australian preschool children. Ophthalmol. 2012;119:138-144. https://doi.org/10.1016/j. ophtha.2011.06.024

14. Multi-Ethnic Pediatric Eye Disease Study Group. Prevalence of amblyopia and strabismus in African American and Hispanic children ages 6 to 72 months the multi-ethnic pediatric eye disease study. Ophthalmol. 2008;115:1229-1236. https://doi.org/10.1016/j.ophtha.2007.08.001

15. Yekta A, Fotouhi A, Hashemi H, et al. The prevalence of anisometropia, amblyopia and strabismus in school children of Shiraz, Iran. Strabismus. 2010;18:104-110. https://doi.org/10.3109/09273972.2010.502957

16. Awan MA, Ahmad I, Khan AA. Prevalence of amblyopia among government middle school children in city of Lahore, Pakistan. Int J Agro Vet Med Sci. 2010;4:41-46.

17. Williams C, Northstone K, Howard M, Harvey I, Harrad RA, Sparrow JM. Prevalence and risk factors for common vision problems in children: Data from the ALSPAC study. Br J Ophthalmol. 2008;92:959-964. https://doi.org/10.1136/ bjo.2007.134700

18. Marmamula S, Ravuri CS, Boon MY, Khanna RC. A cross-sectional study of visual impairment in elderly population in residential care in the South Indian state of Andhra Pradesh: A cross-sectional study. BMJ Open. 2013;3(3):e002576. https:// doi.org/10.1136/bmjopen-2013-002576

19. Stevens G, White R, Falxman SR, et al. Global prevalence of visual impairment and blindness: Magnitude and temporal trends, 1990-2010. Ophthalmology. 2013;120:2377-2384. https://doi.org/10.1016/j.ophtha.2013.05.025

20. Bourne RR, Stevens GA, White RA, et al. Causes of vision loss worldwide, 19902010: A systematic analysis. Lancet Glob Health. 2013;1(6):e339-e349.

21. Prevention of Blindness Union. Data on blindness and visual impairment in EMR and Africa [homepage on the Internet]. [cited 2015 Jun 01]. Available from: www. pbunion.org/blinddata.htm

22. Al Ghamdi AH, Rabiu M, Saad H, Yorston D, Kuper H, Polack S. Rapid assessment of avoidable blindness and diabetic retinopathy in Taif, Saudi Arabia. $\mathrm{Br}$ Ophthalmol. 2012;96(9):1168-1172.

23. Almdal TP, Handlos LN, Valerius M, et al. Glycaemic threshold for diabetes-specific retinopathy among individuals from Saudi Arabia, Algeria and Portugal. Diabetes Res Clin Pract. 2014;103(3):e44-e46.

24. Aldebasi YH, Reddy PR, Nair VG, Ahmed MI. Screening for diabetic retinopathy: The optometrist's perspective. Clin Opt. 2015;7:1-14.

25. Kingdom of Saudi Arabia-Ministry of Health Portal [homepage on the Internet] [cited 2017 Oct 01] Available from: www.moh.gov.sa/en/pages/Default.aspx

26. Smith DP. The 75th anniversary of the World Council of Optometry. Clin Exp Optom. 2002;85(4):210-213.

27. AOAExcel ${ }^{\mathrm{TM}}$ and Jobson Optical Group. An action-oriented analysis of the state of the optometric profession [homepage on the Internet]. 2013 [cited $2015 \mathrm{Apr}$ 02]. Available from: http://www.reviewob.com/Data/Sites/1/soop_070120134. pdf

28. Optometrists Association Australia. Position statement [homepage on the Internet] Primary Health Care and Optometry; 2010 [cited 2015 Apr 02]. Available from: http://www.optometrists.asn.au/media/278113/position_statement_primary_ health_care and optometry.pdf

29. Kiely PM, Horton P, Chakman J. The Australian optometric workforce 2009. Clin Exp Optom 2010;93:330-340.

30. Optometrists and health care delivery in Canada. Role document of Canadian Association of Optometrists [homepage on the Internet]. [cited 2015 Apr 02]. Available from: http://31347.vws.magma.ca/media/docs/en/optometry/ optometrist_and_health_care_EN.pdf

31. Murthy GV, Raman U. Perspectives on primary eye care. Community Eye Health 2009;22(69):10-11.

32. Grosvenor T. Primary Care Optometry. London, United Kingdom: ButterworthHeinemann, Elsevier Health Sciences; 2006. 
33. Aldebasi Y. Young public's awareness to refractive error deficiency. Int J Health Sci. 2011;5(1):9-15.

34. Cunningham D, Whitley W. Integrated eye care in the United States [homepage on the Internet]. [cited 2012 Sept 15]. Available from: http://bmctoday.net/ crstodayeurope/2011/06/article.asp?f=integrated-eye-care-in-the-unitedstates

35. Project report: Assessment of optometric service delivery in Tanzania [homepage on the Internet]. Community Eye Health. [cited 2016 Dec 12]. Available from: http://library.Ishtm.ac.uk/MSc_CEH/2010-11/100300.pdf

36. Raman U. Human resources for eye care: Changing the way we think. Community Eye Health. 2009;22(69):12.

37. Naidoo K, Ravilla D. Delivering refractive error services: Primary eye care centres and outreach. Community Eye Health J. 2007;20(63):42-44.

38. Oam BA, Resnikoff S. The role of optometry in vision 2020. Community Eye Health. 2002;15(43):33-36.

39. Baker H, Ratnarajan G, Harper RA, Edgar DF, Lawrenson JG. Effectiveness of UK optometric enhanced eye care services: A realist review of the literature. Ophthalmic Physiol Opt. 2016;36(5):545-557.

40. Al Motowa S, Khandekar R, Al-Towerki A. Resources for eye care at secondary and tertiary level government institutions in Saudi Arabia. Middle East Afr J Ophthalmol. 2014;21(2):142-146.

41. Alotaibi AZ. Optometry services in Saudi Arabia. Global J Health Sci 2017;9(8):9198. https://doi.org/10.5539/gjhs.v9n8p91

42. World Health Organization. Media centre. Visual impairment and blindness [homepage on the Internet]. Fact sheet N²82. 2014 [cited 2015 Nov 15]. Available from: http://www.who.int/mediacentre/factsheets/fs282/en/
43. International Statistical Classification of Diseases and Related Health Problems. 10th Revision (ICD-10)-WHO Version for 2016. Chapter VII. Diseases of the eye and adnexa [homepage on the Internet]. [cited 2015 Nov 15]. Available from: and adnexa [homepage on the Internet]. [cited 2015 Nov 15]. Avail
http://apps.who.int/classifications/icd10/browse/2016/en\#/H53-H54

44. Wong TY, Foster PJ, Hee J. Prevalence and risk factors for refractive errors in adult Chinese in Singapore. Invest Ophthalmol Vis Sci. 2000;41:2486-2494.

45. Schellini SA, Durkin SR, Hoyama E, et al. Prevalence and causes of visual impairment in a Brazilian population: The Botucatu Eye study. BMC Ophthalmol. 2009;9:1-9.

46. Dandona R, Dandona L. Refractive error blindness. Bull World Health Organ. 2001;79(3):237-243.

47. Falkenberg HK, Langaas T, Svarverud E. Outcomes of large sample vision screening among school children aged 7-15 years in Norway. In: Abstracts of ARVO Annual meeting, April 2014. Invest Ophthal Vis Sci. 2014;55:5570.

48. Dhital A, Pey T, Stanford MR. Visual loss and falls: A review. Eye. 2010;24(9):14371446.

49. Leat SJ, Gurwood A, Kergoat H, Pesudovs K, Eperjesi F. Geriatric vision care- a new look at the old. J Optom. 2009;2(3):101-102. https://doi.org/10.3921/joptom.2009.101

50. Costello E, Edelstein JE. Update on falls prevention for community dwelling older adults: Review of single and multifactorial intervention programs. J Rehabil Res adults: Review of single and
Dev. 2008;45(8):1135-1152.

51. De Souza N, Cui Y, Looi S, et al. The role of optometrists in India: An integral part of an eye health team. Indian J Ophthalmol. 2012;60(5):401-405. https://doi. org/10.4103/0301-4738.100534

52. American Optometric Association. Eye and vision care in the patient-centered medical home. Approved by AOA Board of Trustees January 17, 2008 [homepag on the Internet]. [cited 2016 Dec 13] Available from: http://www.aoa.org/ documents/advocacy/Medical\%20Home\%20Policy\%20Paper.pdf 


\section{Appendix 1}

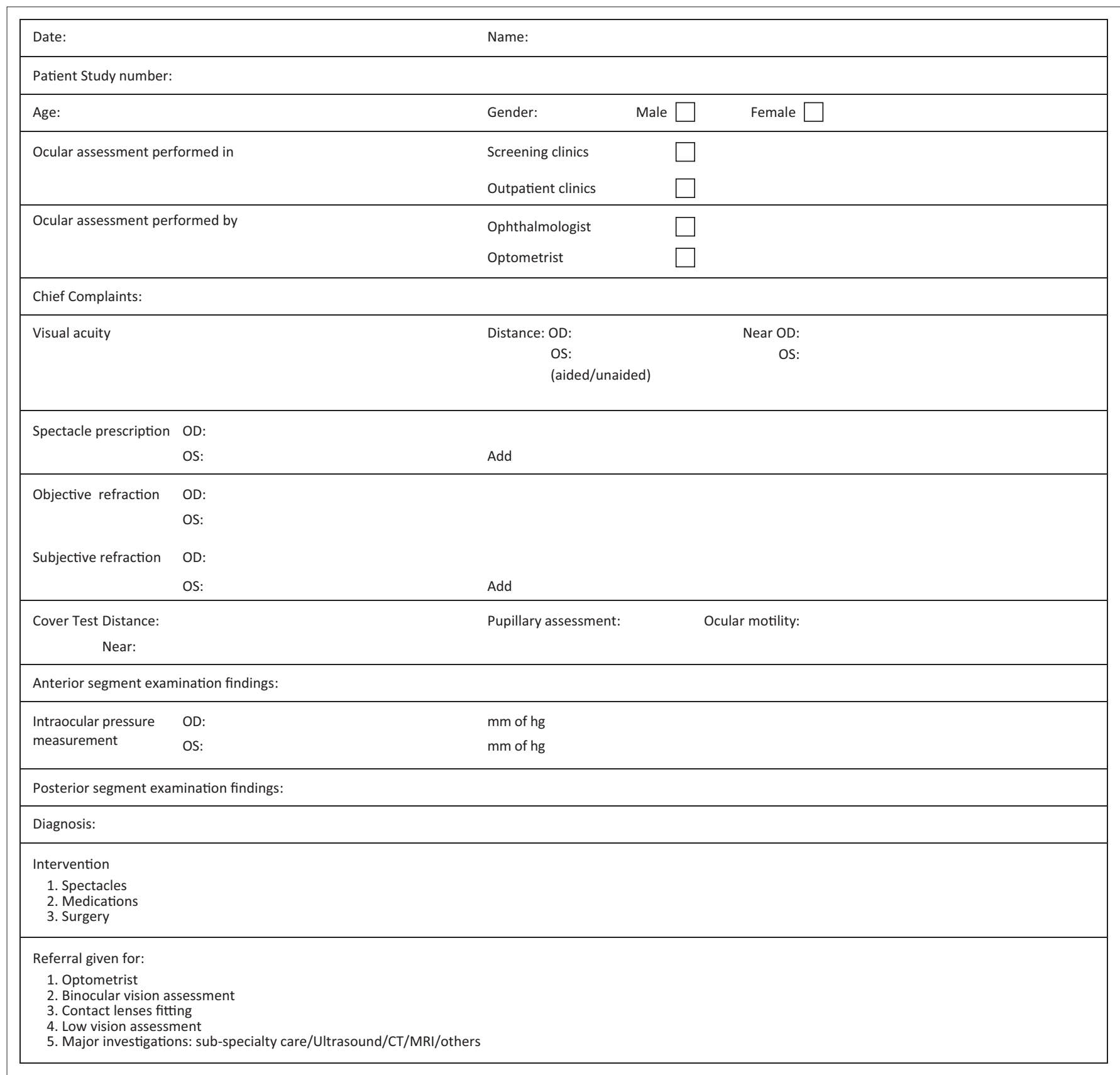

FIGURE 1-A1: Data collection form. 